\title{
THERMAL BEHAVIOUR OF AGITATED GAS-LIQUID REACTORS WITH A VAPORIZING SOLVENT/AIR OXIDATION OF HYDROCARBONS
}

\author{
K. R. WESTERTERP* and P. R. J. J. CROMBEEN \\ Department of Chemical Engineering. Twente University of Technology, P.O. Box 217, 7500 AE \\ Enschede, The Netherlands
}

(Received 12 August 1982; accepted 24 January 1983)

\begin{abstract}
Many highly exothermic gas-liquid reactions are carried out with a vaporizing solvent, which after condensation is returned to the reactor. In this way the liberated reaction heat for a large part is absorbed by the cooling water flowing through the condensor. In order to determine the influence of this evaporation on the behaviour of an agitated gas-liquid tank reactor a model second order reaction was studied. The temperature dependence of the enhancement factor is strongly affected by the solvent evaporation. The infuence of several design and operation parameters such as liquid residence time, dilution of reactant with solvent, air excess in the gas phase and reactor pressure on the conversion and the reactor pressure is demonstrated. Multiplicity for the chosen model reaction will only occur under rather severe conditions. The theory developed is applied to an industrial air oxidation of a hydrocarbon.
\end{abstract}

\section{INTRODUCTION}

An introduction to the vast literature on agitated gas-liquid reactors and on the estimation of the values of the relevant design and operation variables for this reactor type is a.o. given by Charpentier[1], van Landeghem[2], Barona[3] and Joshi, Pandit and Sharma [4].

The agitated gas-liquid reactor behaves thermally as an autothermal CSTR, for which the theory was first developed by van Heerden [5]. On the basis of his work the gas-liquid CSTR was further evaluated and the phenomena of multiplicity, hysteresis and limit cycles were shown to exist both theoretically [6-13] and experimentally $[14,15]$. Sharma, Hoffman and Luss[16] were the first to include the influence of the evaporation losses in the heat balance of gas-liquid CISTR's, when they investigated consecutive gas-liquid reactions. They concluded that evaporation losses are an important factor and can induce a large error in the prediction of high temperature steady states.

Beskov, Charkova and Novikov[17] studied a nonenhanced first order gas-liquid reaction $(\varphi<0.2)$ with evaporation losses and with negligible mass transfer resistances in both the gas and the liquid phase $\left(k_{L}=\infty, k_{G}=\infty\right)$. They demonstrated the existence of three possible operating points. Because they assumed in their study $k_{L}^{-1}$ to be zero, they found two operating points less than Hoffman, Sharma and Luss [8]. If they would have included finite values for both $k_{G}$ and $k_{L}$ they could have found under certain conditions even seven possible operating points, because the "resistances" $k^{-1}, k_{L}$ and $k_{G}$ each individually exhibit their own temperature behaviour and each one of them can give rise to their own operating points. In general it can be said that-if there are $n$ resistances in

*Author to whom correspondence should be addressed. series - we can expect $2 n+1$ possible operating points of which $n+l$ are stable.

Hanhart, Kramers and Westerterp [18] a.o. showed that the gas is perfectly mixed at higher agitation rates, so that the assumption of perfect mixing in the gas phase is the more prudent one. Then the solution of the material balances for the analysis of the thermal behaviour of a gas-liquid CSTR with vaporizing solvents still depend on the feed gas composition: if the gas consists of a pure reactant, it can react away completely at low gas loads, if it also contains an inert compound-such as nitrogen in air oxidations - the gas flows in the material balance can be related to the inert gas flow through the reactor sections. Both cases are not essentially different and we will restrict our discussion to the second case only and consider the air oxidation of paraxylene [19], where the oxygen in the air and the hydrocarbons react according to second order kinetics with a chemical rate of the type $k c_{A} c_{B}[20]$.

\section{THE REACTOR SECTION}

A schematic sketch of an air oxidation gas-liquid reactor section is given in Fig. 1. Air and liquid are fed separately into the reactor, the liquid feed consists of solvent and reactant. The reaction heat is partly carried away by the vapours produced which together with the nitrogen and non-converted oxygen are flowing to a steam producing cooler-condensor. Here the gas and vapour stream are cooled to a temperature somewhat above the steam temperature. The condensate is separated in a separator and returned to the reactor. The gases and the remainder of the vapours pass to a second cooler-condensor, which is cooled by water, and a second separator. Also this condensate is returned to the reactor; the off-gases are now fed through a high pressure scrubber, where the last traces of solvents are removed, and let off into the atmo- 


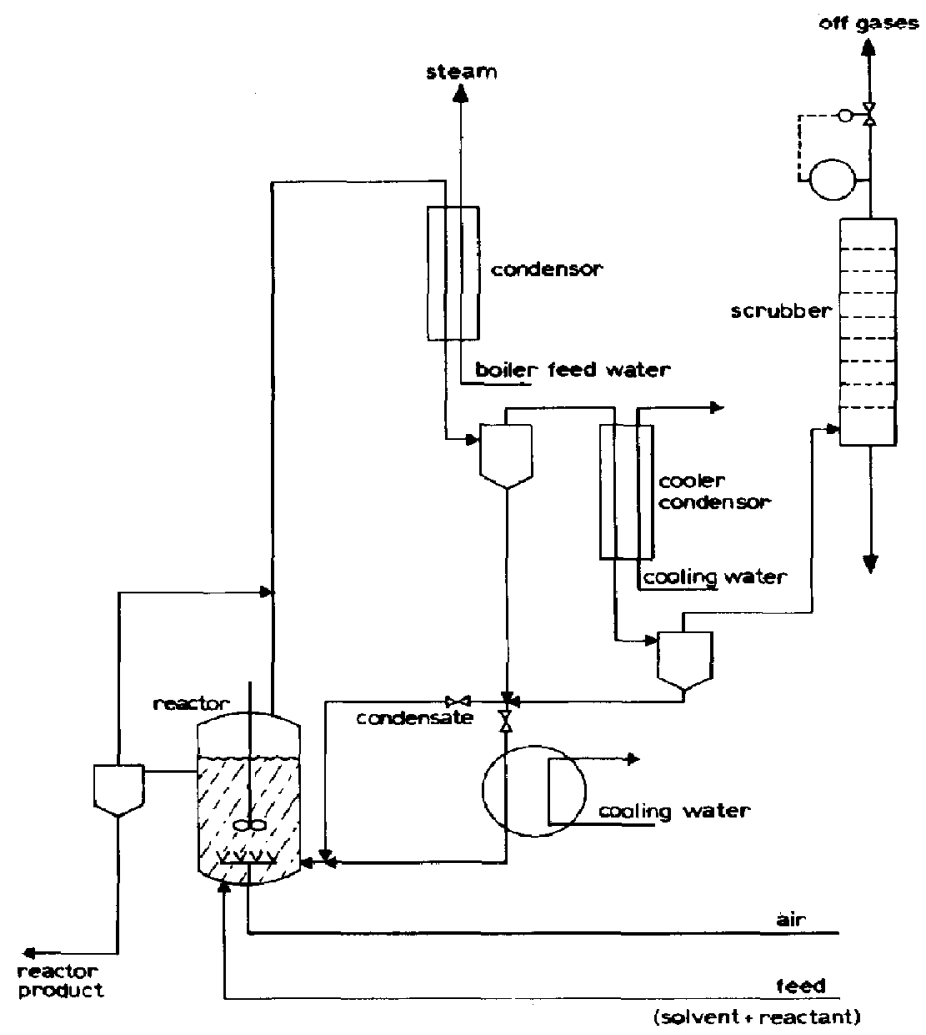

REACTOR SECTION

Fig. 1. The gas-liquid reactor section in an air oxidation plant.

sphere via a pressure control valve. The first condensate can also be cooled in a cooler before being returned to the reactor; the reason for this will be explained later. The liquid reactor product after separation of the entrained gas bubbles goes to the product separation section, which will not be discussed here.

\section{DERIVATION OF THE BASIC EQUATIONS FOR}

THE ATR OXIOATION OF PARAXYLENE

We first make the following assumptions with respect to the agitated gas-liquid reactor: the gas flow and the liquid phase are perfectly mixed; the pressure is constant in the reactor and independent of the liquid height; mass transfer coefficients, the gas hold-up and the specific interfacial area are constant over the whole reaction volume; the vapour-liquid are ideal and can be described by Raoult's law.

The oxidation of paraxylene $(B)$ with oxygen $(A)$ to acid $(P)$ can be described by:

$$
v A+B \rightarrow P+(v-1) W
$$

in which $W$ is the reaction water formed, further $v=3$. The reactant $B$ is dissolved in a solvent $S$. For this reaction it is known [19] that the product $P$ is insoluble and crystallizes out. Moreover, the solvent acetic acid has a much lower boiling point that reactant $B$ and conversions generally are high so that the vapour pressure of $B$ is negligible. In this case the mole fractions in the liquid phase are related to the conversion $\zeta_{B}$ of the reactant $B$ by:

$$
\begin{aligned}
\dot{x}_{S} & =\frac{c_{S o} / c_{B o}}{1+(v-2) \zeta_{B}+c_{S o} / c_{B o}} \\
x_{W} & =\frac{(v-1) \zeta_{B}}{1+(v-2) \zeta_{B}+c_{S o} / c_{B o}} \\
x_{B} & =\frac{1-\zeta_{B}}{1+(v-2) \zeta_{B}+c_{S o} / c_{B o}}
\end{aligned}
$$

if $c_{B D}$ is the molar concentration of the reactant and $c_{S O}$ of the solvent in the reactor feed and if the density of the reaction mixture remains constant. Further $x_{\lambda}=0$.

The total reactor pressure equals

$$
p=p_{A}+p_{B}+p_{P}+p_{W}+p_{S}+p_{N 2}
$$

in which $N 2$ refers to nitrogen. In our case $p_{B}$ and $p_{P}$ are $\simeq 0$ and vapour pressures and liquid compositions 
are related by $p_{S}=p_{S}{ }^{0} x_{S}$ for the solvent, in which $p_{S}{ }^{0}$ is the vapour pressure of pure solvent at the reactor temperature in the liquid mixture and by $p_{W}=\mathrm{He} x_{W}$, in which $\mathrm{He}$ is the Henry coefficient at the reactor temperature for the reaction water formed. The vapour pressure and the Henry coefficient were derived from the data of Othmer, Silvis and Spiel [35].

Now, if a molar stream of $\Phi_{p L} c_{B p}$ of reactant $B$ is fed to the reactor, the molar amount of oxygen consumed for complete conversion of the reactant is equal to $v \Phi_{v L} c_{B o}$. An excess of oxygen has to be applied in order to maintain a certain partial pressure of oxygen in the gas phase, which is assumed to be perfectly mixed. If we supply an amount of oxygen of $X$ times the required stoichiometric amount, the molar quantity of oxygen fed to the reactor is $\nu \Phi_{v L} c_{B a} X$ and the accompanying amount of nitrogen $\Phi_{N 2}$ then equals $\frac{79}{21} v \Phi_{v L} c_{B o} X$.

The value of $X$ cannot be chosen freely, because an explosive mixture in the gas phase has to be avoided. The nitrogen passes untouched through the reactor, the cooler-condensor and scrubber to the atmosphere. We assume, that the vapours are completely condensed and returned to the reactor, in this case $\Phi_{v L \text { in }} \simeq \boldsymbol{\Phi}_{v L \text { sut }} \simeq \boldsymbol{\Phi}_{u L}$, if we neglect the increase in liquid volume by the water formation. For the oxygen the overall material balance is:

$$
\begin{aligned}
& v \Phi_{v L}\left(c_{B o}-c_{B}\right)=\Phi_{A \text { in }}-\Phi_{A \text { out }}=\Phi_{A \text { in }}-\frac{p_{A}}{p_{N 2}} \Phi_{N 2 \text { out }} \\
& =v \Phi_{v L} c_{B o} \zeta_{B}=v \Phi_{v L} c_{B o} X-79 p_{A} v \Phi_{v L} c_{B o} X / 21 p_{N 2}
\end{aligned}
$$

which can be rewritten with $p_{B}=p_{P}=0$ into:

$$
\zeta_{B}=X \frac{p-\frac{100}{21} p_{A}-p_{W}-p_{S}}{p-p_{A}-p_{W}-p_{S}}
$$

Here we used the relation:

$$
\frac{p_{A}}{p_{N 2}}=\frac{p_{A}}{p-\left(p_{A}+p_{W}+p_{S}\right)} .
$$

With eqn (3) we can eliminate $p_{N 2}$ and find for the partial pressures of oxygen and nitrogen in the gas phase:

for oxygen:

$$
\frac{p_{A}}{p}=\frac{X-\zeta_{B}}{\frac{100}{21} X-\zeta_{B}}\left(1-\frac{p_{W}+p_{S}}{p}\right)
$$

and for nitrogen:

$$
\frac{p_{N 2}}{p}=1-\frac{p_{A}}{p}-\frac{p_{W}+p_{S}}{p}=\frac{\frac{79}{21} X}{\frac{100}{21} X-\zeta_{B}}\left(1-\frac{p_{W}+p_{S}}{p}\right) .
$$

If the mass transfer resistance in the gas phase is negligible or $k_{G}=\infty$ and $m p_{A} / R T=c_{A}$, the conversion rate of the oxygen in the reactor is given by the mass balance:

$$
v \boldsymbol{\Phi}_{v L} c_{B o} \zeta_{B}=J_{A} a V_{r}=k_{L} E_{A} a V_{r} * m p_{A} / R T
$$

Further the reaction between oxygen and reactant $B$ in the gas phase is of the second order. Two expressions for the enhancement factor $E_{A}$ for second order reactions, that cover the whole range of values of $\varphi$, (where $\varphi$ is the Hatta number) for the chemically enhanced region of $\varphi>2$ have been developed by Porter[21] and by Kiskinevskii, Kormenho and Popa[22]. Alper [23] proved that both give very good coverage with the original results of Van Krevelen and Hoftijzer [24], so that we will use the simpler one, that of Porter:

$$
E_{\wedge}=1+\left(E_{\infty}-1\right)\left[1-\exp \left(\frac{1-\varphi}{E_{\infty}-1}\right)\right]
$$

in which

$$
E_{\infty}=1+\frac{v D_{A} c_{B}}{D_{B} c_{A}}
$$

and

$$
\varphi=\frac{1}{k_{L}} \sqrt{k c_{B} D_{A}}
$$

If the reaction heat is $\left(-\Delta H_{r}\right)_{A}$ and the heat of absorption $\left(-\Delta H_{a}\right)_{A}$ per kmole of $A$ reacted and absorbed, the heat production rate $H P R$ in the reactor is:

$$
\text { HPR }=v\left[\left(-\Delta H_{\mathrm{r}}\right)_{A}+\left(-\Delta H_{a}\right)_{A}\right] \Phi_{b L} c_{B a} \zeta_{A^{*}}
$$

For the heat removal four different contributions can be distinguished:

(1) The heat absorbed by the cold liquid feed, which equals $\Phi_{v L} \rho_{L} c_{p L}\left(T-T_{0}\right)$ if $T$ is the reactor and $T_{0}$ the liquid feed temperature.

(2) The heat absorbed by the air blown into the reactor, which equals $M_{\text {air }} c_{p \text { air }} * \frac{100}{21} v \Phi_{v L} c_{B o} X[(T-$ $\left.\left.T_{0}\right)-\left(T_{0 \text { air }}-T_{0}\right)\right]$ if $T_{0 \text { air }}$ is the air inlet temperature.

(3) The heat carried away by the vapours. If $\Phi_{\mathrm{mol}} w$ and $\Phi_{\text {mol } s}$ are the molar streams and $\Delta H_{\text {vap } w}$ and $\Delta H_{\text {vaps }}$ the heats of evaporization of water and solvent respectively, we find with $\Phi_{\text {mol } i}=p_{i} \Phi_{M 2} / p_{N 2}$ for this contribution

$$
\frac{\left[p_{W}\left(\Delta H_{\mathrm{vap}}\right)_{W} M_{W}+p_{S}\left(\Delta H_{\mathrm{vap}}\right)_{S} M_{S}\right] * \frac{79}{21} v \Phi_{v L} c_{B b} X}{p-\left(p_{W}+p_{S}+p_{A}\right)} .
$$

(4) The heat absorbed by the condensate returned to the reactor. If the vapors are completely condensed, this contribution is:

$$
\frac{\left(p_{W} M_{W} c_{p W}+p_{S} M_{S} c_{p S}\right)\left[\left(T-T_{0}\right)-\left(T_{\text {cond }}-T_{0}\right)\right] * \frac{79}{21} v \Phi_{\nu L} c_{B o} X}{p-\left(p_{W}+p_{S}+p_{A}\right)}
$$


Here $T_{\text {cond }}$ is the temperature of the condensate entering into the reactor.

The sum of these contributions amounts to the heat withdrawal rate HWR. But first we substitute temperature dependent expressions for the physical and chemical parameters:

solvent vapour pressure:

$$
p_{s}=p_{S \infty} \exp \left(-T_{s} / T\right)
$$

Henry coefficient for water:

$$
H e=H e_{\infty} \exp \left(-T_{W} / T\right)
$$

diffusion coefficient:

$$
D_{A}=D_{A \infty} \exp \left(-T_{D} / T\right)
$$

mass transfer coefficient:

$$
k_{L}=\text { const } * \sqrt{D}
$$

solubility coefficient:

$$
m=m_{\infty} \exp \left(+T_{M} / T\right)
$$

reaction rate constant:

$$
k=k_{\infty} \exp \left(-T_{\kappa} / T\right) .
$$

Here the constant in $k_{L}$ is not a true physical constant but depends on conditions in the reactor.

We define a dimensionless reactor temperature by:

$$
\theta=\frac{T_{K}}{T_{0}^{2}}\left(T-T_{0}\right)
$$

so that for the reaction rate constant, if $\beta=T_{0} / T_{K}$, now is obtained:

$$
=k_{0} \exp \left(\frac{\theta}{1+\beta \theta}\right)
$$

and also

$$
\frac{T}{T_{0}}-1+\beta \theta
$$

If we now abbreviate the term $\exp (\theta /(1+\beta \theta))$ by using the symbol $(\mathcal{B}$, then for example the solvent vapour pressure at the temperature $T$ can be written as:

$$
p_{s}^{0}=p_{s o}^{0}\left(B^{*}\right.
$$

where the index 0 is used to express "at the temperature $T_{0}$ ", so that $p_{S o}^{0}$ is the vapour pressure of solvent at $T_{0}$, and where $\alpha=T_{S} / T_{K^{\prime}}$

Similar expressions are obtained for the other parameters.
Dividing both the HPR and the HWR terms by $\rho_{L} c_{p L} \Phi_{\mathrm{v} L}$ and introducing the dimensionless temperature defined by eqn (8), the energy balance HPR = HWR becomes after addition of the four different contributions to HWR:

$$
\begin{gathered}
\theta_{\text {ad }} \zeta_{B}=A \theta+(1-A) \theta_{\text {air } 0}+ \\
\frac{\left[B+C\left(\theta-\theta_{\text {cond }}\right)\right](B)^{\alpha}+\left[D+F\left(\theta-\theta_{\text {cond }}\right)\right]\left(B^{\gamma}\right.}{79 X}\left(1-P_{w}\left(D^{\alpha}-p_{s}\left(D^{\gamma}\right)\right.\right.
\end{gathered}
$$

In this eqn (12) the conversion $\zeta_{A}$ is still a function of temperature. The value of $\zeta_{B}$ as a function of $\theta$ can be found by solving the material balance (5) combined with (4) and (6), which after introducing $\theta$ and dividing by $\Phi_{\mathrm{vL}} c_{B o}$ becomes:

$$
\begin{aligned}
\zeta_{B}= & \frac{D a\left(\Theta^{0.5 \delta \cdots \sigma}\right.}{1+\beta \theta} * \frac{X-\zeta_{B}}{\frac{100}{21} X-\zeta_{B}} \\
& *\left(1-P_{W}\left(B^{\alpha}-P_{S}\left(B^{\nu}\right) E_{A}\right.\right.
\end{aligned}
$$

in which $E$ is given by eqn (6) and where

$$
\varphi=(H)^{0.5}\left(1-\zeta_{B}\right)^{0.5} * R
$$

and

$$
\begin{aligned}
E_{\infty}= & \frac{\left(1-\zeta_{B}\right)(H)^{\circ}(1+\beta \theta)}{\left(\frac{X-\zeta_{B}}{(100 / 21) X-\zeta_{B}}\right)\left(1-P_{\omega}(H)^{\alpha}-P_{S}(B)^{\nu}\right)} \\
& * Q+1 .
\end{aligned}
$$

The significance of all the dimensionless constants is given in Table 1 .

\section{THERMAL STABILITY AND MULTIPLICITY}

In eqn (12) the HWR-the r.h.s.-approaches infinity in case $\boldsymbol{P}_{W}(\boldsymbol{H})^{*}+\boldsymbol{P}_{s}(\boldsymbol{H})^{*} \rightarrow 1$ : the HWR is infinitely large when the sum of the partial pressures of the solvent and the water formed equals the total reactor pressure. In this case so many vapours evolve that the mole fraction of oxygen and nitrogen in the gas phase have approached the limit zero. This sets a hypothetical limit to the maximum attainable reactor temperature, which is reached at the boiling point of the reaction mixture.

Due to the vapour pressures of the solvent and the water formed the partial pressure of the oxygen at the interface is being reduced and consequently also the HPR. If the conversion $\zeta_{B}$ and $X$ or the excess air supplied would remain constant, the influence of the evaporation is shown in Fig. 2, where the absorption rate $J$ is plotted as a function of the reactor temperature. Due to the volatility of the liquid the oxygen partial pressure at the gas-liquid interface is reduced.

In Fig. 3 the usual plot of the heat production and heat withdrawal rate is given for a certain case and as calculated with eqns (12) and (13). We observe the 
Table 1. The constants in eqns (12) and (13)

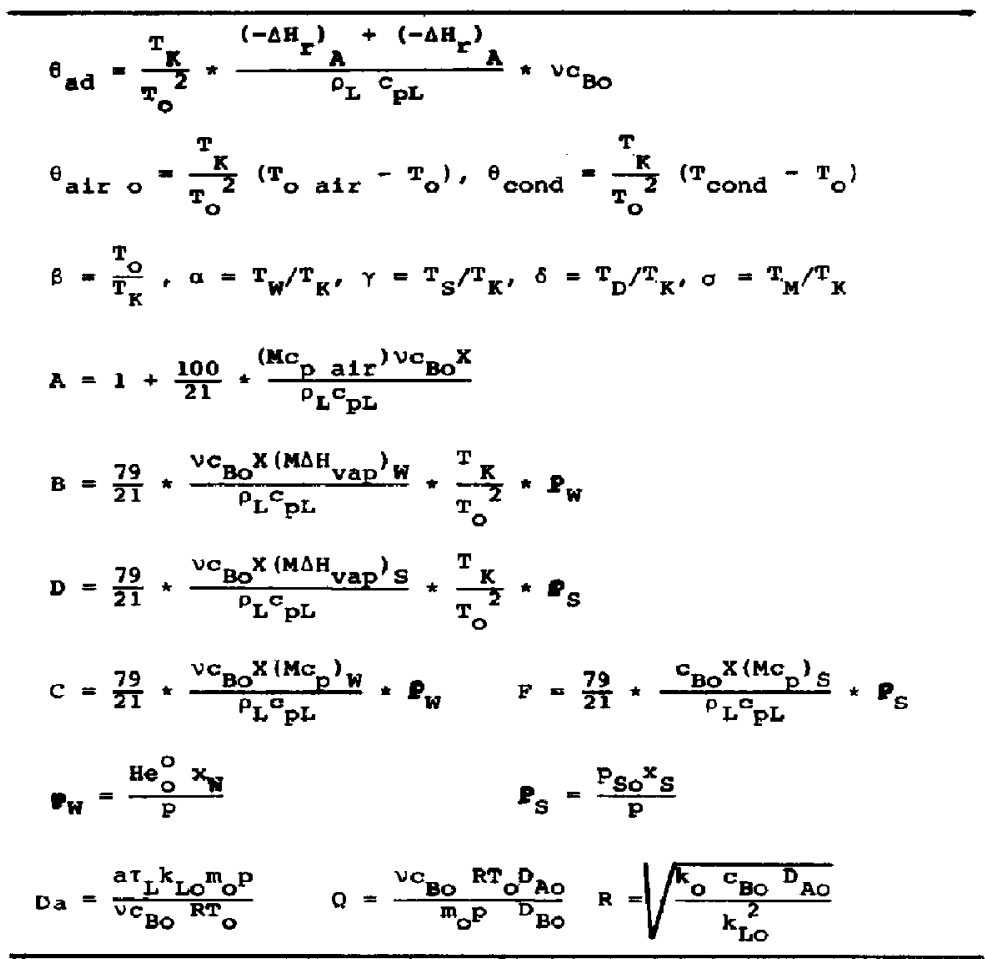

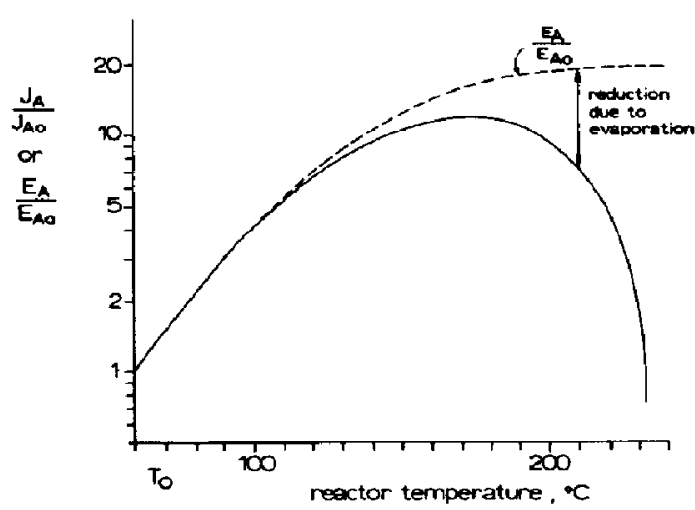

Fig. 2. The conversion rate for a second order reaction with (thick line) and without (dotted line) evaporation at constant reactant concentrations as a function of temperature in an agitated gas-liquid reactor. $C_{s}=0.2 \mathrm{kmol} / \mathrm{m}^{3} ; X=1.10$; $p=2.5 \mathrm{MPa} ; T_{0}=60^{\circ} \mathrm{C}$ for all streams; further see-Table 2 .

usual $S$-shape for the HPR at lower reaction temperatures, the same as we met with for the single phase CISTR. However, at very high reactor temperatures the HPR suddenly drops because here the vapour pressures of water and/or solvent increase rapidly and as a consequence the oxygen partial pressure is greatly reduced so that no high conversions can be achieved anymore. When $p_{w}+p_{S}=p$ the reaction has stopped completely and $\zeta_{B}$ dropped to zero: the gaseous reactant cannot diffuse into the liquid anymore. For the HWR we observe the usual start with a straight line. As soon as water and solvent start to evaporate, the HWR is enhanced and finally reaches infinity as soon as $p_{w}+p_{s}=p$. The upper stable operating point is found when HWR = HPR.

More information on the same case of Fig. 3 is given in Fig. 4: we see that the conversion $\zeta_{B}$ is high over the whole range of reactor temperatures and drops to zero at the maximum attainable temperature. The partial pressure $p_{A}$ of oxygen, divided by the $p_{A o}$ if no evaporation would take place, is gradually reduced and reaches the limit zero. The mass of vapour produced per unit of mass of liquid feed introduced - the evaporation ratio-increases rapidly as a function of $T$ in the neighbourhood of the upper stable operating point.

The multiplicity characteristics of this reactor type can be investigated by plotting:

$$
\frac{\text { HWR }}{\text { HPR }}=f(\theta) .
$$

For the values of $\theta$ where $f(\theta)=1$ operating points are oblained. This is done in Fig. 5 for the same case as in Fig. 3. Here only one stable operating point is obtained. If the reactor inlet temperature $T_{0}$ is reduced as shown in Fig. 6 the reactor will develop multiplicity, whereas curve 2 with a lower $T_{0}$ demonstrates three 


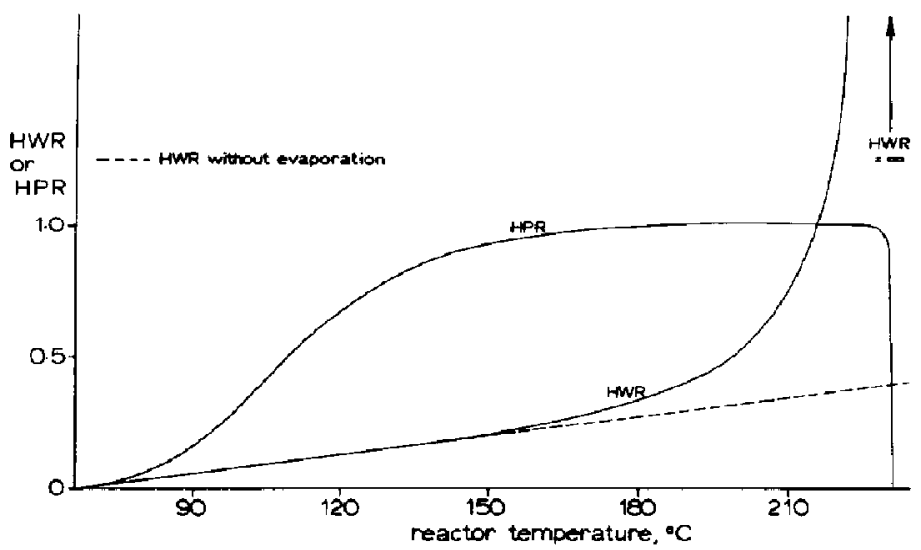

Fig. 3. Heat production and withdrawal rates in an agitated gas-liquid reactor with a vaporizing solvent. $\tau_{L}=5400 \mathrm{~s} ; p=2.5 \mathrm{MPa} ; X=1.10 ; T_{0}=60^{\circ} \mathrm{C}$ for all streams; further see Table 2.

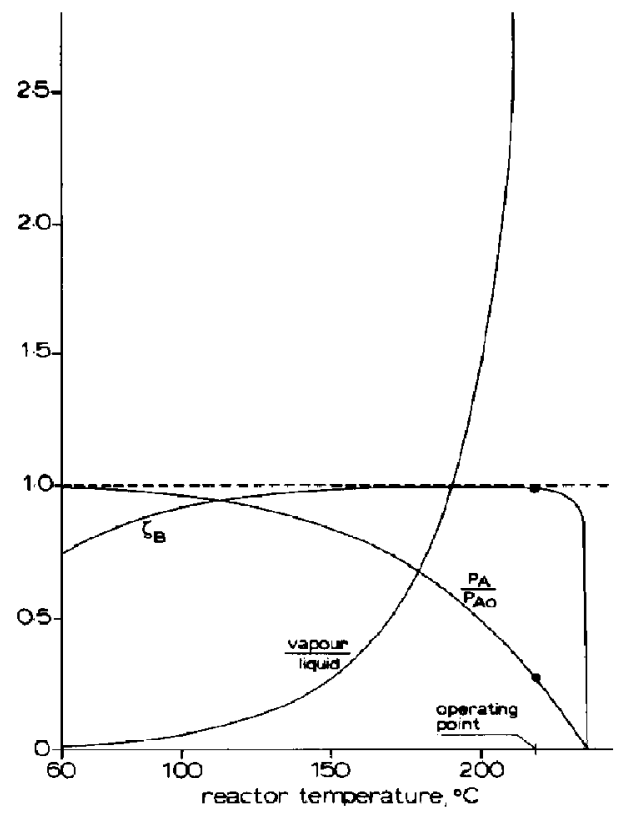

Fig. 4. The conversion, oxygen partial pressure reduction and vapour formation in an agitated gas-liquid reactor with a vaporizing solvent as a function of the reactor temperature. Conditions as in Fig. 3.

operating points of which the intermediate one is unstable. This is in principal the same behaviour as of the autothermal tank reactor.

\section{A REACTOR DESIGN}

It is now required to design a reactor for a xylene conversion $\zeta_{B}>0.98$, with a feed concentration of $c_{B o}=2.2 \mathrm{kmol} / \mathrm{m}^{3}$ and a liquid residence time of one hour. Air under pressure and the xylene solution are available at $20^{\circ} \mathrm{C}$.

For the reactor and the reaction system pertinent

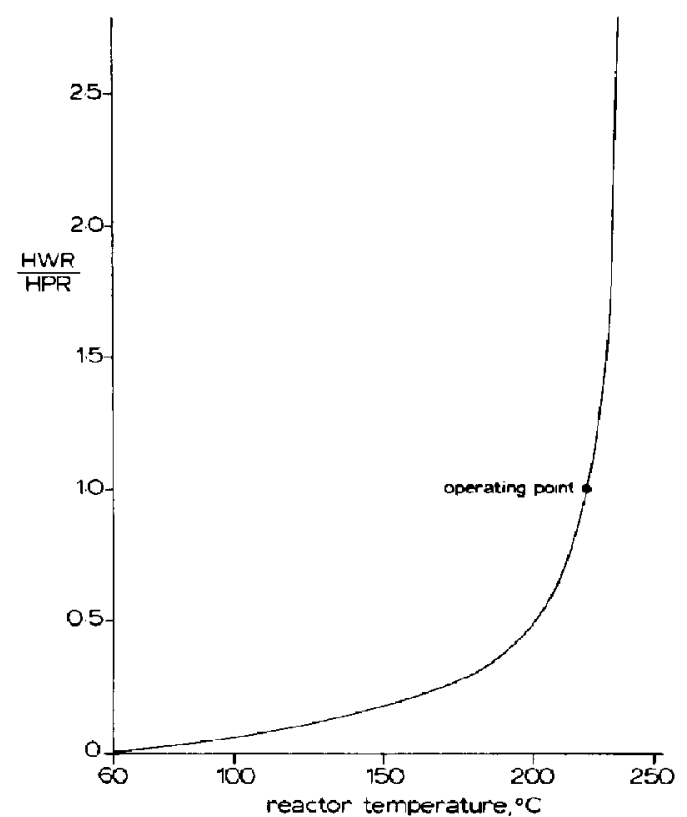

Fig. 5. The $f(\theta)=$ HWR/HPR curve for the case of Fig. 3 . Conditions as in Fig. 3.

data are given in Table 2 including data obtained in a preliminary design. The estimate of the specific interfacial area needs some explanation. From the early work of a.o. Calderbank [25] and Westerterp, Van Dierendonck and De Kraa [26] and later by Reith [27], Van Dierendonck [28, 29] and Miller [30] and recently by Nishikawa, Nakamura, Yagi and Hashimoto [20] the work on correlation of specific interfacial areas still continues. Moreover, very little of the effect of pressure on gas-liquid dispersions is known, but results till now $[31,32]$ indicate that hardly any influence of pressure has to be expected. We have used the work of Van Dierendonck $[28,29]$ and found for the agita- 


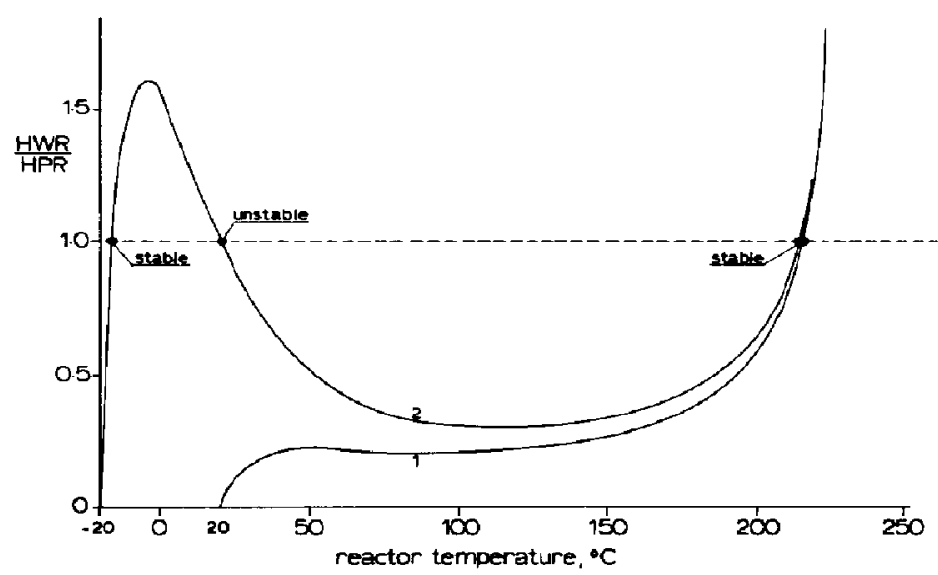

Fig. 6. The $f(\theta)$ curve for the reaction system of Fig. 6, but at lower reactor inlet temperatures. Data as in Table 2, except $c_{B_{0}}=2.2 \mathrm{kmol} / \mathrm{m}^{3} ; \tau_{L}=540 \mathrm{~s} ; p=2.5 \mathrm{MPa} ; X=1.10 ; T_{0 \text { air }}=20^{\circ} \mathrm{C} ; T_{\text {cond }}=100^{\circ} \mathrm{C} ;$ (1) $T_{0}=20^{\circ} \mathrm{C} ;$ (2) $T_{0}=-20^{\circ} \mathrm{C}$.

Table 2. Data for the xylene oxidation

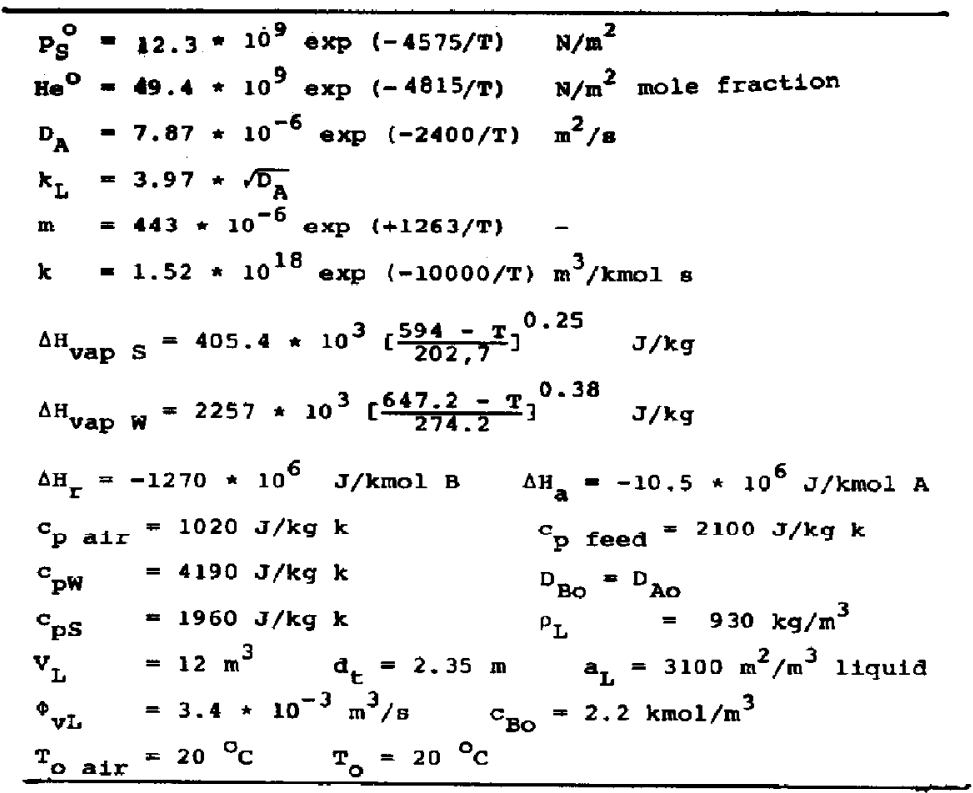

tion level chosen in our preliminary design a gas holdup of $\epsilon=0.33$ and an interfacial area of $2100 \mathrm{~m}^{2} / \mathrm{m}^{3}$ reaction volume or $3100 \mathrm{~m}^{2} / \mathrm{m}^{3}$ liquid volume at near operating conditions. These data have been used in our calculations of the reactor performance.

Several design variables have been studied more in detail at $\tau_{L}=3600 \mathrm{~s}$ by using the eqns (12)-(15). The results are shown in Table 3 and in Fig. 7, where $f(\theta)$ is plotted vs the reactor temperature. We then observe for the design variables studied:

-If the reactant concentration is increased to $c_{B O}=4.4 \mathrm{kmol} / \mathrm{m}^{3}$ the conversion drops to a too low value. At the same time air is supplied at such a rate, that linear gas velocities can become too high and excessive liquid entrainments would occur.

-A reactor pressure of $2.0 \mathrm{MPa}$ gives a too low and of $2.5 \mathrm{MPa}$ an adequate conversion. At $p=3.0 \mathrm{MPa}$ a conversion higher than desired is obtained. The gain in conversion will probably not offset the higher compression costs for the air.

-An air excess of $5 \%(X=1.05)$ gives a too low, of $10 \%$ an adequate and $X=1.20$ gives a conversion higher than desired. Also in this case the yield increase will probably not offset the $9 \%$ higher air compression costs.

- The installation of a condensate after cooler is advantageous because it reduces the reactor tern- 


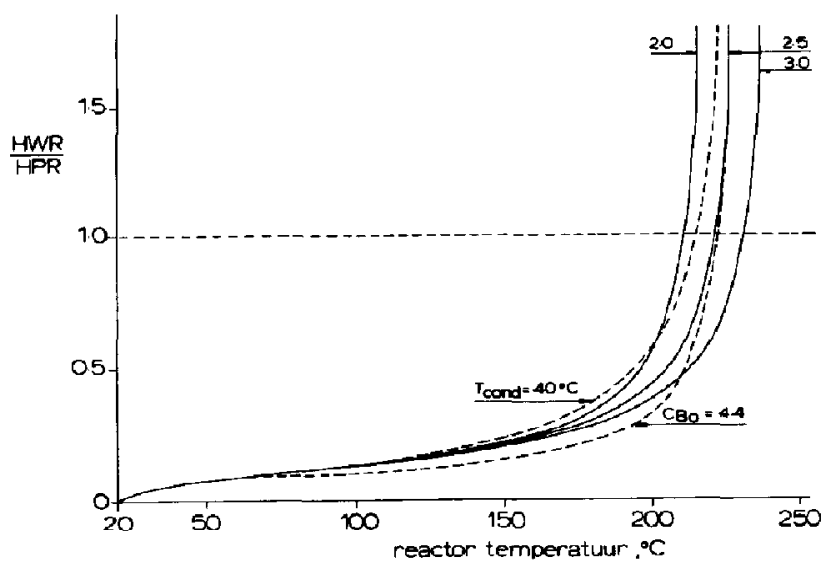

Fig. 7. $f(\theta)$ curves for different design conditions of the reactor design. Reactor pressure in MPa.

Table 3. Influence of design variables on the performance of the reactor

\begin{tabular}{|c|c|c|c|c|c|c|c|}
\hline \multicolumn{8}{|l|}{ Conditions } \\
\hline Reactor pressure, MPa & 2.5 & 52.0 & 2.5 & 3.0 & 2.5 & $2.5 \quad 2.5$ & \\
\hline $\begin{array}{l}\text { Reactant concentrations } \\
c_{10} / \mathrm{mol}^{\prime} / \mathrm{m}^{3}\end{array}$ & 4.4 & 42.2 & 2.2 & 2.2 & 2.2 & 2.22 .2 & \\
\hline Air ratio & 1.1 & 101.10 & 1.10 & 1.10 & 1.051 & 1.201 .1 & \\
\hline Condensate temperature, o & 170 & 170 & 170 & 170 & 170 & 170 & \\
\hline \multicolumn{8}{|l|}{ Resultts } \\
\hline Value of $\mathrm{De}$ (see table 1 ) & 5.2 & 8.3 & 10.4 & 12.5 & 10.4 & 10.4 & 10.4 \\
\hline Reactor temperature, ${ }^{\circ} \mathrm{C}$ & 220 & 208 & 220 & 231 & 221 & 219 & 214 \\
\hline Convergion, $\zeta_{B}$ & 0.940 & 0.958 & 0.977 & 0.988 & 0.955 & 0.991 & 0.984 \\
\hline
\end{tabular}

perature and increases the conversion, simultaneously the cooler-condensors can be designed with lower heat transfer areas. Without the after cooler the combined condensate streams will have a temperature of around $170^{\circ} \mathrm{C}$. The $T_{\text {cond }}$ can become lower if a water cooled cooler-condensor is used, but then no steam can be produced anymore and this is an attractive feature of the design of Fig. 1. With an after cooler the total condensate can be cooled to around $40^{\circ} \mathrm{C}$, so that per $\mathrm{kg}$ liquid evaporated more heat is absorbed. Now the stable operating point is reached at a lower evaporation ratio, which results in a lower partial pressure of vapours in the gases leaving the reactor: therefore the oxygen partial pressure and consequently also the conversion are higher.

To meet the requirements for the reaetor performance we recommend on the basis of the results in Fig. 8 and Table 3: an air excess of $10 \%(X=1.10)$, a reactant concentration of $c_{B o}=2.2 \mathrm{kmol} / \mathrm{m}^{3}$, a reactor pressure of $p=2.5 \mathrm{MPa}$ and the installation of a condensate aftercooler.
Multiplicity does not occur as can be seen from Fig. 7. For the same operating conditions except lower values of $\mathrm{Da}-$ which implicates lower agitation rates resulting in lower values of $a /(1-t)$ multiplicity can occur as demonstrated in Fig. 8, in our case for $D a<0.29$. This corresponds to a value of $a /(1-\epsilon)=86 \mathrm{~m}^{2} / \mathrm{m}^{3}$ liquid. This value is so low that even without agitator or for an agitator breakdown the reactor would maintain a high stable operating temperature, because the air flow itself would already create a larger interfacial area. Therefore we can safely conclude that in our reactor and with our reaction system no multiplicity can occur. Also at start-up only a high operating point can be reached. This does not mean that we can do without agitator: intense agitation is needed for the high conversion required.

\section{DISCUSSION OF RESULTS AND CONCLUSIONS}

Curve 2 in Fig. 6 exhibits a maximum, a minimum and an inflexion point. The shape of this curve is strongly influenced by the value of the dimensionless number $D a$ : for increasing values of $D a$ the shape of the 


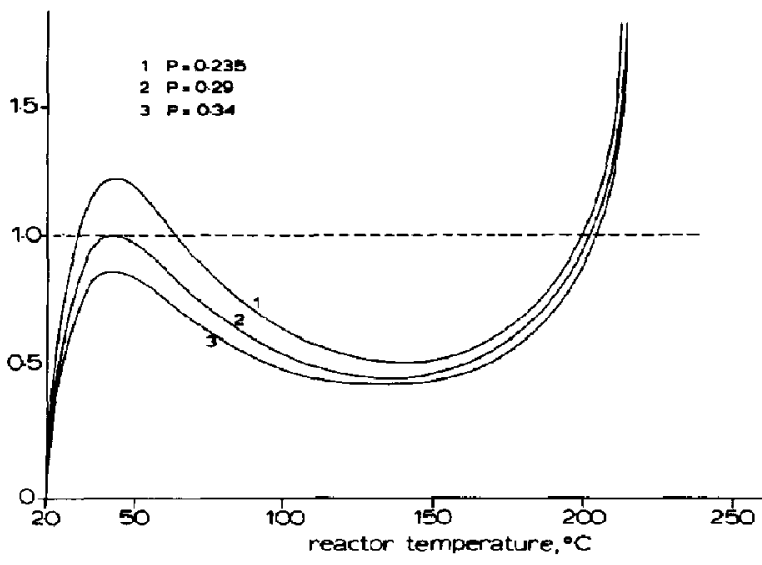

Fig. 8. Multiplicity in the reactor.

curve gets less pronounced and finally for a certain value of $D a$ the three points coincide. $D a$ is a kind of a Damköhler number $k_{L o} a \tau_{L}$ times the reactant concentration ratio $m_{0} p / R T v c_{b_{o}}$ and contains as important variables the liquid residence time, the specific interfacial area as determined by the agitation level and the inlet temperature of the liquid feed to the reactor. After the maximum, minimum and inflexion point have coincided, so for higher values of $D a$, a horizontal line will have only one intersection with the HWR/HPR curve: this means that only one operating point is possible and multiplicity does not occur anymore.

For low values of $\mathrm{Da}$ three points of intersection can occur for all values of HWR/HPR between the maximum and the minimum. As HPR in eqn (12) is given by $\theta_{a x} \zeta_{B}$ and further HWR and $\zeta_{B}$ are exclusive functions of $\theta$, this means that from the maximum and minimum we can determine the values of $\theta_{a d}$ or also $c_{B o}$ between which multiplicity will occur. The HWR/ HPR vs $\theta$ curve enables us to derive from one single plot the entire region where multiplicity is present. This has been discussed more in detail elsewhere [33].

The choice of the solvent and the concentration of the reactant in the solvent are important variables. From the economic point of view reactant concentration in the liquid phase has to be as high as possible to reduce the reactor product separation expenses. The solvent vapour pressure characteristics and its vaporization heat must be such that high conversions are reached in the desired temperature range at the lowest possible reactor pressure. The very steep rise of the HWR-curve at temperatures near the boiling point of the liquid enables us to produce intermediate products by the selection of suitable reactor pressures or suitable solvents. This is explained qualitatively in Fig. 9, where a possible HPR-curve is shown [34] for a reaction system $A \rightarrow P \rightarrow Q$. By selecting a suitable solvent for case 1 mainly product $P$ is produced and by applying a higher reactor pressure or a higher boiling solvent in case 2 product $Q$ is produced.

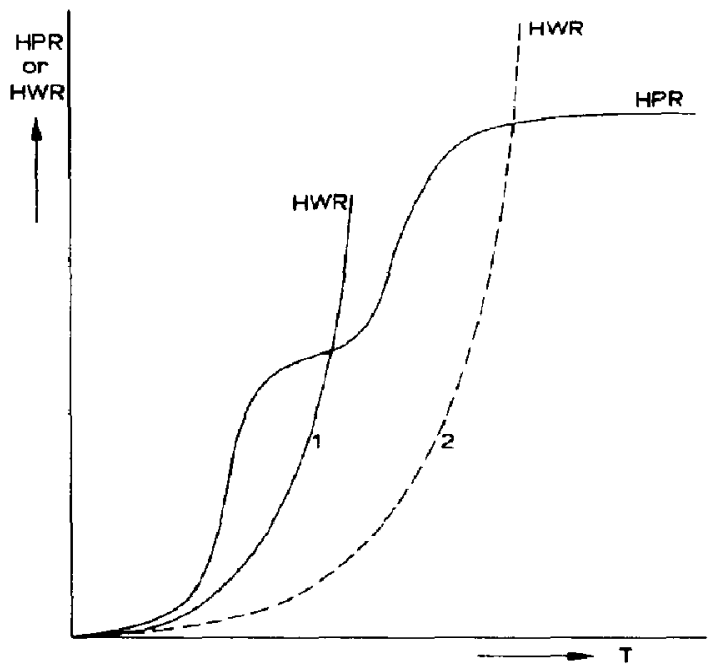

Fig. 9. Control of selectivity for a consecutive reaction. In case 1 the intermediate product and in case 2 the final product is produced by applying a higher reactor pressure or a higher boiling solvent.

We may conclude that the use of a vaporizing solvent to remove the reaction heat in highly exothermic gas--liquid reactions in general lead to thermally quite stable reactors and that a plot of the HWR/HPR vs the reactor temperature is a very useful tool to analyse multiplicity and thermal stability phenomena in chemical reactors.

\section{NOTATION}

$a$ interfacial area per unit of reactor volume, $\mathrm{m}^{2} / \mathrm{m}^{3}$

$c$ concentration, $\mathbf{k m o l} / \mathrm{m}^{3}$

$c_{p}$ heat capacity, $\mathrm{J} / \mathrm{kg} \mathrm{K}$

$D$ diffusion coefficient, $\mathrm{m}^{2} / \mathrm{s}$

$d_{t}$ reactor diameter, $\mathrm{m}$

$E_{A}$ enhancement factor

$E$ activation energy of the reaction, $\mathrm{J} / \mathbf{k m o l}$

He Henry coefficient for water, $\mathrm{N} / \mathrm{m}^{2}$ mole fraction

HPR heat production, $J / s$ or -

HWR heat withdrawal rate, $J / s$ or -

$\Delta H_{r}$ reaction heat, $\mathrm{J} / \mathbf{k m o l}$

$\Delta H_{a}$ absorption heat, $\mathrm{J} / \mathrm{mol}$

$\Delta H_{\text {vap }}$ heat of evaporation, $\mathrm{J} / \mathrm{kg}$

$J_{A}$ mole flux of $A$ through gas-liquid interface, $\mathrm{kmol} / \mathrm{m}^{2} \mathrm{~s}$

$k$ second order reaction rate velocity, $\mathbf{m}^{3} / \mathbf{k m o l ~ s}$

$k_{G}, k_{L}$ mass transfer coefficients, $\mathrm{m} / \mathrm{s}$

$M$ molecular weight, $\mathrm{kg} / \mathrm{kmol}$

$m$ solubility coefficient $\left(c_{L} / c_{G}\right)$

$n$ number of resistances in series

$p$ total reactor pressure, $\mathrm{N} / \mathrm{m}^{2}$

$p_{i}$ vapour pressure of component $i$ in re- 
actor outlet and at gas-liquid interface, $\mathrm{N} / \mathrm{m}^{2}$

$p_{i}^{o} \quad$ vapour pressure of pure component $i$, $\mathbf{N} / \mathbf{m}^{2}$

$R$ gas constant, $\mathrm{J} / \mathrm{kmol} \mathrm{K}$

$T$ temperature of reactor, $\mathrm{K}$ or ${ }^{\circ} \mathrm{C}$

$T_{\text {air } 0}$ temperature of air inlet, $\mathrm{K}$ or ${ }^{\circ} \mathrm{C}$

$T_{\text {cond }}$ condensate return temperature, $\mathrm{K}$ or ${ }^{\circ} \mathrm{C}$

$T_{i}$ activation temperature of physical and chemical parameters, $\mathbf{K}$

$T_{0} \quad$ liquid feed temperature, $\mathrm{K}$ or ${ }^{\circ} \mathrm{C}$

$V$, reactor volume, $\mathrm{m}^{3}$

$x$ molfraction in liquid phase

$X$ ratio of air supplied/stoichiometric amount

$\alpha, \gamma, \delta, \sigma$ ratio of activation energies to that of the reaction

$\beta R T_{0} / E$ or $T_{0} / T_{K}$

$\theta$ dimensionless reactor temperature

(B) $\exp (\theta /(1+\beta \theta))$

$\nu$ stoichiometric coefficient

$\zeta_{B}$ relative conversion of $B$

$\rho_{L}$ liquid density, $\mathrm{kg} / \mathrm{m}^{3}$

$\tau_{L}$ residence time of the liquid, $s$

$\varphi$ Hatta number

$\Phi_{v L}$ liquid flow rate, $\mathrm{m}^{3 / \mathrm{s}}$

$\Phi_{\text {mol } i}$ molar flow rate of component $i$, $\mathrm{kmol} / \mathrm{s}$

$A, B, C, D, F, \quad$ dimensionless groups, see Table 1

$Q, R, \theta_{a d}$

Subscripts

$\begin{aligned} A & \text { reactant in the gas phase } \\ B & \text { reactant in the liquid phase } \\ D & \text { diffusion } \\ G & \text { gas phase } \\ K, r & \text { reaction } \\ L & \text { liquid phase } \\ M & \text { solubility } \\ 0 & \text { at liquid inlet temperature } \\ S & \text { solvent } \\ W & \text { water }\end{aligned}$

\section{REFERENCES}

[1] Charpentier J. C., Am. Chem. Soc. Symp. Ser. 197874 223.

[2] Landeghem H. van, Chern. Engng Sci. 1980351912.

[3] Barona N., Hydrocarbon Proc. 1979 58(7) 179.
[4] Joshi J. B., Pandit A. B. and Sharma M. M., Chem. Engng Sei. 198237813.

[5] Van Heerden C., Ind. Engng Chem. 1953451242.

[6] Schmitz R. A. and Amundson N. R., Chem. Engng Sci. $196318265,391,415,447$.

[7] Luss D. and Amundson N. R., Chem. Engng Sci, 1967 22267.

[8] Hoffman L. A., Sharma S. and Luss D., A.I.Ch.E.J. 197521318.

[9] Raghuram S. and Shah Y. T., Chem. Engng J. 197713 81.

[10] Raghuram S., Shah Y. T. and Tierney J. W., Chem. Engng J. 19791763.

[11] Huang D. T. J. and Varma A., A.L.Ch.E.J. 198127481 , 489.

[12] Huang D. T. J. and Varma A., Chem. Engng J. 198121 47.

[13] Singh C. P. P., Shah Y. T. and Carr N. L., Chem. Engng J. 198223101 .

[14] Ding J. S. Y. and Luss D., Ind. Engng Chem. Fundls 19741376.

[15] Hancock M. D. and Kenney C. N., Chem. Engng Sci. 197732629.

[16] Sharma S., Hoffman L. A. and Luss D., A.I.Ch.E.J. 197622324.

[17] Beskov W. S., Charkova T. V. and Novikov E. A., Theor. Found. Chem. Tech. 197913 120, in Russian.

[18] Hanhart J., Kramers H. and Westerterp K. R., Chem. Engng Sci. 196318503.

[19] Kirk-Othmer, Encyclopedia of Chemical Technology, 3rd Edn, Vol. 17, p. 746. Wiley, New York 1982.

[20] Zscherpe J., Chem. Technik. 197729537

[21] Porter K, E., Trans. Inst. Chem. Engrs 196644 T25.

[22] Kishinevskii M. K., Kormevo T. S. and Popa T. M., Theor. Found. Chem. Engng 19714 641, in Russian.

[23] Alper E., Chem. Engng Sci. 1973232093.

[24] Van Krevelen D. W. and Hoftijzer P. J., Rec. Trav. Chim. 194867563.

[25] Calderbank P. H., Trans. Inst. Chem. Engrs (London) 195836443.

[26] Westerterp K. R., van Dierendonck L. L. and de Kraa J. A., Chem. Engng Sci. 196318157.

[27] Reith T., Br. Chem. Engng 1970151559.

[28] Van Dierendonck L. L., Ph.D. Thesis, Twente University of Technology, The Netherlands 1970.

[29] Van Dierendonck L. L., Fortuin J. M. H. and Vandenbos D., Proc. 4th Eur. Symp. Chem. Reaction Engng, Brussels, Pergamon Press, Oxford 1971.

[30] Miller D. H., A.I.Ch.E.J. 197420445 .

[31] Teramoto M., Tai S. Nishii K. and Teranishi H., Chem. Engng J. 19748223.

[32] Sridhar T. and Potter O. E., Ind. Engng Chem. Fundls 19801921 .

[33] Westerterp K. R., van Swaaij W. P. M., and Beenackers A. A. C. M., Chemical Reactor Design and Operation. Wiley, New York 1983.

[34] Westerterp K. R., Chem. Engng Sci. 196217423.

[35] Othmer D. F., Silvis S. J. and Spiel A., Ind. Engng Chem. 1952441864. 